\title{
Analysis of Spatial Distribution of Jas's Larch Inchworm Outbreak Area
}

\author{
Xiaojun Huang ${ }^{1,2,3,4}$, Yaowen Xie ${ }^{2}$, Yulong Bao ${ }^{1,3,4}$, Enkhnasan $D^{5}$, Ganzorig $B^{6}$, Peiling Li ${ }^{1}$ \\ ${ }^{1}$ College of Geographical Science, Inner Mongolia Normal University, Huhhot 010022, China \\ ${ }^{2}$ College of Earth and Environmental Sciences, Lanzhou University, Lanzhou730000, China \\ ${ }^{3}$ Key Laboratory of Remote Sensing \& Geography Information System, Inner Mongolia Normal \\ University, Huhhot 010022, China \\ ${ }^{4}$ Inner Mongolia Key Laboratory of Disaster and Ecological Security on the Mongolia plateau, \\ Inner Mongolia Normal University, Huhhot 010022, China \\ ${ }^{5}$ Institute of General and Experimental Biology, Mongolian Academy of Sciences, Ulan Bator, \\ Mongolia \\ ${ }^{6}$ Forest research development center, Ministry of Nature Environment and Tourism, Ulan Bator, \\ Mongolia
}

\section{雅氏落叶松尺蠖暴发区空间分布特征分析 黄晓君 ${ }^{1,2,3,4}$, 颕耀文 ${ }^{2}$, 包玉龙 ${ }^{1,3,4}$, Enkhnasan $D^{5}$, Ganzorig $\mathrm{B}^{6}$, 李佩玲 ${ }^{1}$ \\ ${ }^{1}$ 内蒙古师范大学地理科学学院, 呼和浩特 010022 , 中国 2 兰州大学资源环境学院, 兰州 730000 , 中国 ${ }^{3}$ 内蒙古自治区遥感与地理信息系统重点实验室, 呼和浩特 010022 , 中国 ${ }^{4}$ 内蒙古自治区蒙古高原灾害与生态安全重点实验室, 呼和浩特 010022, 中国 5 蒙古国科学院综合与实验生物学研究所, 乌兰巴托, 蒙古国 ${ }^{6}$ 蒙古国自然环境和旅游部森林研究发展中心, 乌兰巴托, 蒙古国}

\begin{abstract}
Jas's Larch Inchworm is a pest that harms larch forest in Mongolia plateau. It is important to study the distribution of Jas's Larch Inchworm outbreak area for effective prevention and control of larch disaster. In this study, the RS data were used to extract pests areas by the change detection-maximum synthesis model, and the pest coverage index was used to extract insect outbreak areas, and then the spatial distribution characteristics of the pest outbreak areas were analyzed from both meteorological and topographic perspectives. The research shows that the Kappa coefficient of extraction of the pest areas is 0.835 , indicating that this method has high accuracy. The pest coverage index can be used to rapidly extract pest outbreak areas,
\end{abstract}

which is a new idea for extracting outbreak area in forest pests. During the incubation period, spawning period and wintering period of pests ,the distribution of pest outbreak areas has spatially different rules for temperature and precipitation conditions. The pest outbreak areas are mainly distributed on Semi-sunny slope or semi-shady slopes with gentle slopes of 1676-2996m above sea level. The research results will provide a reference for the occurrence and development of the Jas's Larch Inchworm.

Keywords: Jas's Larch Inchworm outbreak area; GIS spatial analysis; Pest coverage index; Spatial distribution characteristics

摘要

雅氏落叶松尺蠖是蒙古高原独有严重 危害落叶松林的害虫, 研究其暴发区空间分 
布规律对于有效防控该虫灾害具有重要意 义。本研究利用遥感数据通过变化检测 - 最 大值合成法模式提取害虫发生区, 计算虫害 覆盖指数提取害虫暴发区, 然后从气象和地 形两方面分析了害虫暴发区空间分布特征。 结果显示: (1)提取害虫发生区的Kappa系数 为 0.835 , 说明此方法精度较高; (2)利用虫 害覆盖指数可快速提取害虫暴发区, 这是森 林害虫暴发区提取的一种新思路; (3)在孵化 期、产卵期和越冬期, 害虫暴发区分布对于 气温和降水量具有空间分异规律; (4)害虫暴 发区主要分布在海拔1676 2996m缓坡的半 阳坡或半阴坡上。以上研究成果为雅氏落叶 松尺蠖灾害发生发展规律提供参考依据。

关键词：雅氏落叶松尺蠖暴发区; GIS 空间 分析; 虫害覆盖指数; 空间分布特征

森林病虫害和森林火灾 (全球每年发生 森林火灾具有几十万次 [1]) 是主要威胁森 林生态系统的自然灾害。蒙古高原森林资源 丰富, 森林虫害频发, 其中雅氏落叶松尺蠖 (Erannis jacobsoniDjak) 灾害尤其严重。雅 氏落叶松尺蠖是蒙古高原独有严重危害落 叶松林的害虫。近年来该虫在蒙古国北部频 发, 森林生态系统遭到严重破坏。此灾害逐 年往东扩展, 已对我国北方森林生态屏障安 全有重大威胁。我国高度重视中蒙俄绿色 “一带一路” 建设, 习近平主席多次强调, 要践行绿色发展理念, 着力深化环保合作, 加大生态环境保护力度, 携手打造绿色丝绸 之路。尤其强调我国北方和蒙古国生态安全 问题, 如森林病虫害的攻击。在此背景下, 研究蒙古国雅氏落叶松尺蠖灾害空间分布 特征显得至关重要。

森林虫害信息提取是分析虫害空间分 布特征的前提, 而虫害空间分布特征是揭示 害虫灾害发生发展规律的核心问题。从森林 虫害信息提取来看, 遥感具有时间分辨率、 空间分辨率和光谱分辨率的优势, 目前已成 为大面积森林虫害信息快速提取的主要手 段, 如利用不同年份的 TM5/TM4、TM4/TM3、 TM7/TM4、NDVI、PVI、绿度植被指数 (GVI)、 土壤调节植被指数 (SAVI) 和红边参数指数 等光谱指数并进行比较与分析, 提取森林虫 害信息 [2-9]。从虫害空间分布特征分析来
讲, 一般针对虫害发生影响因素, 分析虫害 分布特征, 如黄晓君等利用影响雅氏落叶松 尺蠖适生性气象指标, 结合害虫分布点和寄 主分布数据, 采用Maxent模型和GIS空间分 析方法分析了雅氏落叶松尺蠖适生区空间 分布特征 [10]; 刘志明等通过1975 1992年 的积温、月平均相对湿度、降水量、温度等 气象站点数据, 分析了干燥度、湿润度、温 雨系数与落叶松毛虫灾害的关系 [11]; 邓刚 利用林业有害生物测报点年均温度、年均最 低温度、年均最高温度、降水量和日照时数 等气象数据, 对黑龙江森林虫害发生进行了 空间区划 [12]; 姜霞等运用2000 2014年贵 州省年平均气温、冬季平均气温和年降水量 等气象数据, 分析了气候变化与贵州省森林 病虫害发生的相关关系 [13]; 刘冬等分析了 我国农、林业害虫分布特征, 并探讨了气象 因素和社会经济因素对我国省级单位空间 中农林业害虫分布的影响 [14]。李艳等采用 1971 2000年气候标准值年值数据集, 利用 相关分析方法, 分析了我国70种典型农林害 虫的地理分布格局与气候要素的关系 [15]。 总的来说, 森林虫害信息遥感提取主要利用 Landsat卫星遥感影像的NDVI、RVI (TM4/TM3、 TM5/TM4和 TM7/TM4)、PVI和GVI等光谱指数 来实现; 森林虫害空间分布特征主要通过气 象因素的影响来探讨。基于此, 笔者利用 Landsat卫星遥感数据, 计算重要光谱指数, 提取蒙古国杭爱省南部雅氏落叶松尺蠖灾 害信息, 并从气象和地形因素出发, 借助GIS 空间分析方法揭示虫害空间分布特征, 为该 虫灾害发生规律提供科学依据。

\section{1 材料与方法}

\section{1 研究数据及预处理}

本研究主要使用的数据由Landsat卫星 影像数据 (2011年7月与2016年8月的2景影 像, 空间分辨率为 $30 \mathrm{~m}$ )、气象站点数据 (2015 年与 2016 年杭爱省 17 个站点冬季最低气温、 5 月降水量和平均气温、10月降水量和平均 气温)、数字高程模型数据 (空间分辨率为 $90 \mathrm{~m})$ 和 2016 年野外虫害调查数据组成。利 用ENVI软件对影像数据进行大气辐射校正 和裁剪处理并对DEM数据进行投影转换及裁 剪处理, 运用ArcGIS软件对气象数据进行空 
间化、投影转换及裁剪处理。研究数据的坐 标与投影系统应统一, 即坐标系统为 WGS1984, 投影为通用墨卡托UTM, 带号为 $47 \mathrm{~N}$ 。

\section{2 研究方法}

本研究以蒙古国杭爱省南部 5 个苏木为 研究区 (图1), 利用遥感和GIS技术方法, 提取雅氏落叶松尺蠖发生区和暴发区, 并从 气象和地形两个方面对害虫暴发区空间分 布进行了探讨。

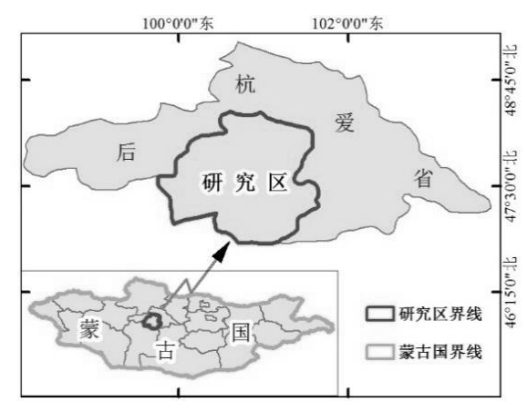

图 1 研究区示意图

\subsection{1雅氏落叶松尺蠖发生区遥感提取方法}

（1）虫害信息提取指标的获取

笔者参考前人相关研究选择近红外波 段反射率（NIR）、比值植被指数（RVI1和 RVI2)、归一化植被指数（NDVI）、垂直植被 指数 (PVI) 和绿度植被指数 (Greenness) 等 6 个对森林植被健康程度较敏感的指数, 作为雅氏落叶松尺蠖发生区信息提取指标。 其中NIR 可从预处理后的Landsat影像直接 获取; RVI1、RVI2和NDVI分别利用NIR/Red、 SWIR1/NIR和（NIR-R）/（NIR+R）等公式计 算可得 ( $R$ 为红波段反射率, SWIR1为短波红 外 1 反射率); PVI 可通过 (NIR $-a R-$ $b) / \sqrt{1+a^{2}}$ 公式计算求得（ $a 、 b$ 分别为土 壤线的斜率和截距); Greenness可利用缨帽 变换获取。从2011年和2016年影像中分别提 取此6个指标。

(2) 害虫发生区提取

2011年杭爱省未发生雅氏落叶松尺蠖, 记为健康年份, 而2016年发生了虫害, 记为 灾害年份。首先对健康年份与灾害年份的提 取指标进行求差, 获得变化信息。其次通过
落叶松分布图斑对变化信息进行掩膜处理 获得落叶松植被变化信息。再次根据各指标 对灾害的响应特征从变化信息中剔除灾害 无关的信息, 获得各指标差的能够表征虫害 的信息, 并分别进行归一化处理。然后对 6 个指标差进行最大值合成, 获得组合后的 1 个综合指标 (值范围为 $0 \sim 1$ )。最后分析 2016 年野外虫害调查点数据与综合指标的关系, 对综合指标阈值并快速提取雅氏落叶松尺 蠖发生区。

\subsection{2 雅氏落叶松尺蠖暴发区提取及空间 分布特征分析方法}

在害虫发生区分布信息遥感提取的基 础上, 首先以 $1000 \times 1000 \mathrm{~m}$ 为单元格, 在研 究区中建立格网, 并计算每个单元网格的虫 害发生面积比例, 记为虫害覆盖指数 (PCI, 见式 1)。其次根据虫害位置及其虫害覆盖指 数, 使用聚类统计量测度蒙古国杭爱省南部 雅氏落叶松尺蠖发生程度空间自相关性, 其 中高一高集聚为害虫暴发区。然后害虫暴发 区与气象因素 (孵化期降水量和平均气温、 产卵期降水量和平均气温和越冬期最低气 温）和地形因素（海拔、坡度和坡向）分别 进行空间叠加分析, 结合直方图分析方法揭 示雅氏落叶松尺蠖暴发区在气象和地形上 的空间分异规律。

$$
\mathrm{PCI}_{i}=\frac{N_{i} \sum_{j=1}^{N_{i}} X_{i j}}{G_{i}} \times 100 \%
$$

式中 $\mathrm{PCI}_{i}$ 为第 $i$ 个单元网格的虫害覆盖 指数, $\mathrm{G}_{i} 、 \mathrm{X}_{i j}$ 分别为单元网格的面积和第 $i$ 个 单元网格中的第 $j$ 个虫害像元的面积, $\mathrm{N}_{i}$ 为第 $i$ 个单元网格中包含的虫害像元数, PCI值越 大虫害严重程度越大。

\section{2 结果与分析}

\section{1 雅氏落叶松尺蠖发生区与暴发区提取}

通过变化检测与最大值合成相结合模式获 得雅氏落叶松尺蠖发生区分布信息提取综 合指标, 与野外调查点数据叠加分析后发现, 当害虫发生时综合指标值为大于 0.95 。从而 对综合指标进行阈值后可得到雅氏落叶松 尺蠖发生区的分布信息, 如图2-A所示。为 害虫发生区分布信息遥感提取精度的评定, 本研究借助野外调查点数据和遥感提取结 
果计算了Kappa系数, 其值为 0.835 。Kappa 系数能检验提取结果与真实结果的一致性, 可评价此提取方法的精度。Kappa系数值表 明提取结果与真实结果一致性极好。可见, 该方法精度较高, 能够有效提取害虫发生区 分布信息。

在获得雅氏落叶松尺蠖发生区分布信 息的基础上, 通过式1计算虫害覆盖指数, 并利用聚类分析方法对虫害覆盖指数进行 聚类分析, 从中提取高-高聚集的部分确定 为害虫暴发区, 得到的结果如图2-B所示。 雅氏落叶松尺蠖暴发区分布与野外虫害调 查数据进行比较得知, 提取结果可信度较高。

\section{2 雅氏落叶松尺蠖暴发区空间分布特征 分析}

\subsection{1 虫害空间分布总体特征}

雅氏落叶松尺蠖暴发区与降水量、气温等分 别空间叠加分析, 得到害虫暴发区空间分布 的气象特征, 并揭示了雅氏落叶松尺蠖对气 象条件的适生性。笔者选择了害虫发育过程 关键阶段的气象因素, 即捊化期: 2016 年 5 月降水量和平均气温、产卵期: 2015 年 10 月降水量和平均气温、越冬期: 2015 年冬季 最低气温 (2015 年 11 月至翌年 1 月)。研究 结果表明, 孵化期: 雅氏落叶松尺蠖暴发区 分布在降水量和平均气温分别介于 29.94 $42.30 \mathrm{~mm}$ 和 $4.77 \sim 8.92^{\circ} \mathrm{C}$; 产卵期: 害虫暴 发区分布在降水量和平均气温分别介于 1. $16 \sim 9.56 \mathrm{~mm}$ 和 $-2.52 \sim 1.53^{\circ} \mathrm{C}$; 越冬期: 害虫暴发区分布在冬季最低气温介于 $-41.64 \sim-31.14^{\circ} \mathrm{C}$ 。为进一步分析雅氏落叶 松尺蠖暴发区在气象上的分异规律, 对暴发

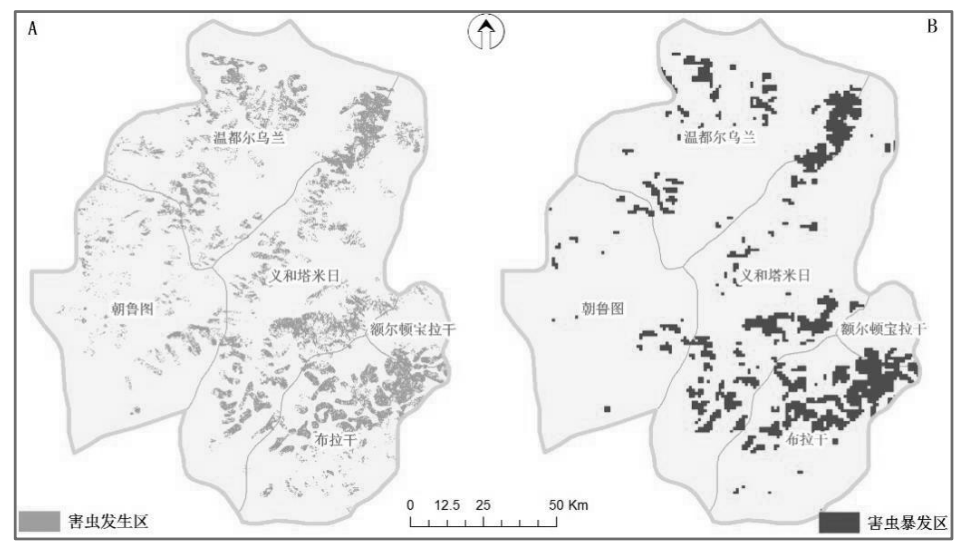

图2 2016年杭爱省南部雅氏落叶松尺蠖灾害空间分布 (A. 害虫发生区分布，B. 害虫暴发区分布)

从图 2-A 可知, 2016 年蒙古国杭爱省南部温 都尔乌兰、义和塔米日、朝鲁图、额尔顿宝 拉干和布拉干等 5 个苏木均发生了雅氏落叶 松尺蠖灾害, 其中温都尔乌兰、义和塔米日 和布拉干苏木的害虫发生面积较大。从图 2-B 得知, 2016 年研究区东南部的义和塔米 日和布拉干苏木雅氏落叶松尺蠖暴发面积 明显较大。害虫暴发区分布与雅氏落叶松尺 蠖生境因素空间分布特征具有密切关系, 如 气象和地形因素。

\subsection{2害虫暴发区空间分布的气象特征}

区气象因素进行了直方图分析 (频率与组距 比值大于 20 的设为主要分布区)。结果显示, 在孵化期雅氏落叶松尺蠖暴发区主要分布 在降水量和平均气温分别介于 38.10 42. $30 \mathrm{~mm}$ 和 $5.62 \sim 8.37^{\circ} \mathrm{C}$ (图 3-A、2-B); 在产卵期害虫暴发区主要分布在降水量和 平均气温分别介于 $7.36 \sim 9.56 \mathrm{~mm}$ 和 $-0.92 \sim$ $1.53^{\circ} \mathrm{C}$ (图 3-C、2-D); 在越冬期主要分布 在冬季最低气温介于 $-34.94 \sim-31.14^{\circ} \mathrm{C}$ (图 $3-E)$ 。这说明在孵化期雅氏落叶松尺蠖不适 宜零下气温和较高湿度的冷雨天气; 在产卵 
期害虫较适宜干旱天气; 越冬期害虫不适宜 过于寒冷天气, 最低气温高于 $-42^{\circ} \mathrm{C}$ 较宜。

\subsection{3 害虫暴发区空间分布的地形特征} 雅氏落叶松尺蠖暴发区与海拔、坡度、坡向 进行空间叠加分析, 得到害虫暴发区空间分
了频数分析。结果表明, 雅氏落叶松尺蠖暴 发区分布在海拔介于 $1676 \sim 2996 \mathrm{~m}$ ，其中主 要分布区在海拔 1916 2471m（见图 4-B); 不同坡度间相比，缓坡上的频数最高（见图 4-A); 不同坡向间相比, 半阳坡上的频数最

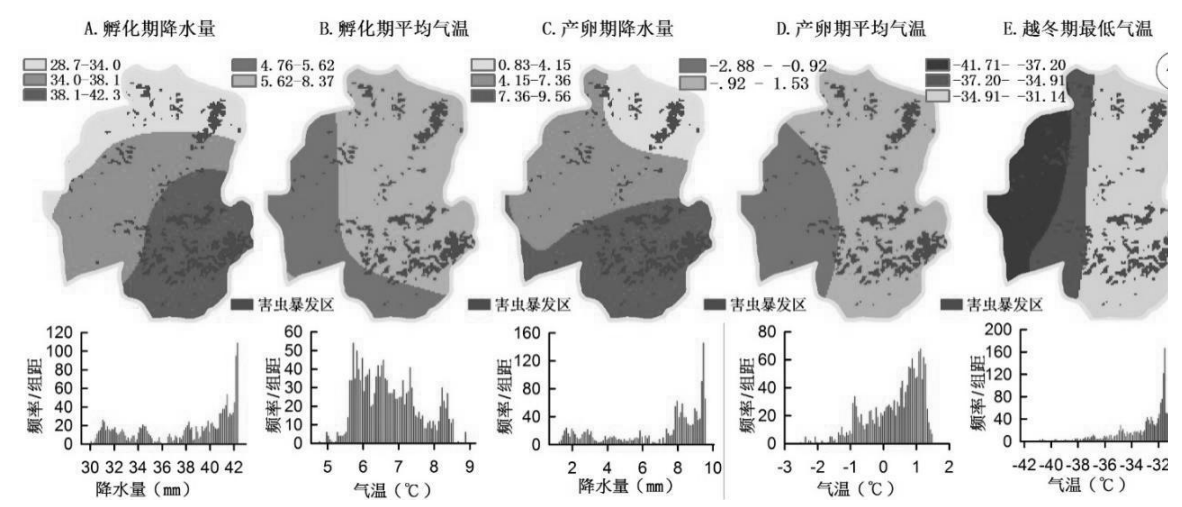

图 3 害虫暴发区空间分布的气象特征及直方图

布的地形特征, 并揭示了害虫对地形条件的 适生性。本研究对害虫暴发区海拔分为 100 个组进行了直方图分析 (频率与组距比值大 于 20 的设为主要分布区), 对坡度分为平坡 $\left(0^{\circ} \sim 5^{\circ}\right)$ 、缓坡 $\left(6^{\circ} \sim 15^{\circ}\right)$ 、斜坡 ( $16^{\circ} \sim 25^{\circ}$ ) 和陡坡 ( $26^{\circ}$ 以上) 进行了 频数分析, 对坡向分为阴坡 (北向)、半阴 坡 (东北向和西北向)、阳坡 (南向) 和半 阳坡 (东向、西向、东南向和西南向) 进行
高, 其次为半阴坡 (见图 4-C)。可见, 雅氏 落叶松尺蠖较适宜中高山缓坡的半阳坡或 半阴坡上生殖发育。

\section{3 结论}

笔者首先选择 NIR、NDVI、RVI1、RVI2、 PVI 和 Greenness 等 6 个指标, 对不同时相 遥感影像进行变化检测, 并结合最大值合成 法求得一个综合指标, 快速提取了雅氏落叶
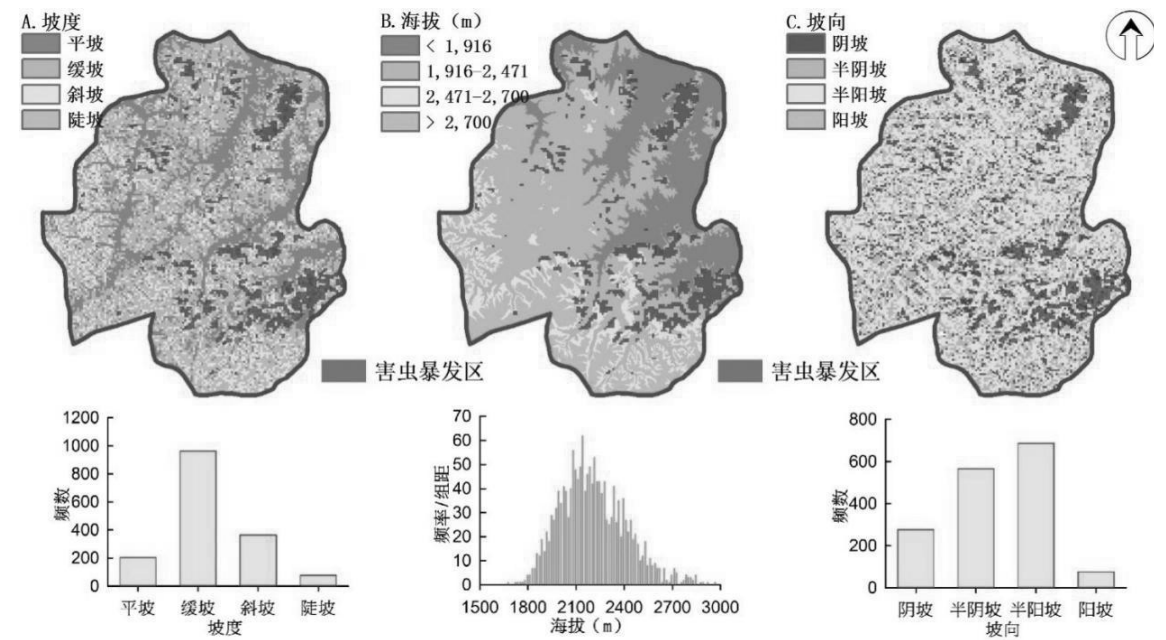

图 4 害虫暴发区空间分布的地形特征及直方图 
松尺蠖发生区分布信息; 其次利用格网法定 义并计算了虫害覆盖指数; 在此基础上, 采 用聚类分析法提取了雅氏落叶松尺蠖暴发 区分布信息; 最后从气温、降水量、海拔、 坡度和坡向等因素分析害虫暴发区空间分 布特征, 得到了以下结论: (1)利用变化检测 一最大值合成法模式, 提取雅氏落叶松尺蠖 发生区分布的 Kappa 系数达 0.835 , 说明此 方法提取精度较高; (2)新定义了虫害覆盖指 数, 并利用该指数可快速提取害虫暴发区, 这是森林害虫暴发区提取的一种新思路; (3) 从气象因素来看, 在孵化期、产卵期和越冬 期, 雅氏落叶松尺蠖暴发区分布对气温和降 水量条件具有空间分异规律; (4)从地形因素 来讲, 雅氏落叶松尺蠖暴发区主要分布在海 拔 1676 2996m 的缓坡的半阳坡或半阴坡上。 以上研究成果对于雅氏落叶松尺蠖发生发 展规律的揭示具有重要参考意义。

\section{Acknowledgements}

This study was supported by National Natural Science Fund (No.61631011) and Inner Mongolia Science and Technology Project (201702116).

致谢

本研究得到了国家自然科学基金 (61631011), 内蒙古科技计划项目 (201702116) 的资助。

\section{参考文献}

[1] Li X H, Wu W J, Lv D B ,et. al. Research on risk assessment and regionalization of forest and grassland fires. Journal of Risk Analysis and Crisis Response, 2012, 2(1): 69-77.

[2] 武红敢, 石进. 松毛虫灾害的 TM 影像监 测技术. 遥感学报, 2004, 8(2): 172-177.

[3] 武红敢, 乔彦友, 黄建文. 利用陆地卫星 TM 数据评估森林病虫害. 遥感技术与应 用, 1994, 9(4):47-51.

[4] 戴昌达. 卫星遥感监测松毛虫灾. 遥感 信息, 1991, (3) :32-34.
[5] Vogelmann J E, Rock B N. Assessing forest damage in high-elevation coniferous forests in Vermont and New Hampsphire using Thematic Mapper data. Remote Sensing of Environment, 1988, 24: 227-246.

[6] Nakane K, Kimura Y. Assessment of pine forest damage by blight based on Landsat TM data and eorrelation with environmental factors. Ecological Researeh, 1992, (7):9-15.

[7] Brockhaus J A. Khorram S,et al. A comparison of landsat TM and SPOT HRV data for use in the development of forest defoliation modes. International Journal of Remote Sensing, 1992, 13(6): 3235-3240.

８］云丽丽, 高国平, 奕庆书, 等. 辽西油松 毛虫虫害的 TM 影像监测技术. 安徽农业 科学, 2010, 38(1) :201-204.

[9] 元兴兰. SPOT-5 遥感影像马尾松毛虫害 信息提取技术研究. 福建农林大 学, 2011.

[10] 黄晓君, 颉耀文, 包玉海, 等. 雅氏落叶 松尺蠖在蒙古高原的适生区分布研究. 西北农林科技大学学报 (自然科学 版), 2018, 46 (4) :1-9.

[11] 刘志明, 晏明, 张旭东, 等. 气象因子对 落叶松毛虫的影响分析. 灾害 学, 2002, 17 (4) : 32-37.

[12] 邓刚. 气象因子的变化对黑龙江省森林 病虫害影响的研究. 东北林业大 学, 2012 .

[13] 姜霞, 郭金鹏, 丁访军. 气候变化对贵州 省森林病虫害的影响. 贵州林业科 技, 2017, 45(4): 44-47.

[14] 刘摇冬, 沈渭寿, 朱四喜, 等. 中国农林 业害虫分布特征及其影响因素. 生态学 杂志, 2014, 33 (12) :3322-3331.

[15]李艳, 吴建国, 谢立勇, 等. 典型农林害 虫分布与气候要素的关系. 环境科学研 究, 2012, 25(5)：533-542. 